\title{
Detection of Ralstonia solanacearum by Loop-Mediated Isothermal Amplification
}

\author{
R. Kubota, B. G. Vine, A. M. Alvarez, and D. M. Jenkins
}

First and fourth authors: Department of Molecular Biosciences and Bioengineering, University of Hawaii, Honolulu 96822; and second and third authors: Department of Plant and Environmental Protection Sciences, University of Hawaii, Honolulu 96822. Accepted for publication 22 May 2008.

\section{ABSTRACT}

Kubota, R., Vine, B. G., Alvarez, A. M., and Jenkins, D. M. 2008. Detection of Ralstonia solanacearum by loop-mediated isothermal amplification. Phytopathology 98:1045-1051.

Ralstonia solanacearum is a pathogenic bacterium that causes wilt in over 200 plant species. Here we report a rapid and sensitive detection of $R$. solanacearum using an isothermal method for copying DNA known as loop-mediated amplification (LAMP). A set of four primers was designed to replicate the gene coding for the flagellar subunit, fliC, and conditions for detection were optimized to complete in $60 \mathrm{~min}$ at $65^{\circ} \mathrm{C}$. Magnesium pyrophosphate resulting from the amplification reaction could be detected optically as an increase in the solution turbidity, and the DNA products spread in a reproducible ladder-like banding pattern after electrophoresis in an agarose gel. Replication of the $f l i C$ gene was detected only from $R$. solanacearum. The detection limit of this LAMP assay was between $10^{4}$ to $10^{6}$ colony forming units $/ \mathrm{ml}$, and the technique may be useful for developing rapid and sensitive detection methods for the $R$. solanacearum pathogen in soil and water.

Additional keywords: gene-based diagnostics.
Ralstonia solanacearum Yabuuchi (Smith) is a pathogenic bacterium that causes wilt in over 200 plant species. Host plants include many important crops such as potato, tomato, banana, peanut, and ginger. Bacterial wilt from $R$. solanacearum results in great economic losses worldwide. Disease incidences of 15 to $55 \%$ have been reported in fresh market tomato in Taiwan, causing losses exceeding 12 million U.S. dollars annually (6). In Hawaii, ginger production was reported to have suffered losses of over 50\% during 1998 and 1999 (34). The bacterium is well adapted to life in soil, where it waits for a host plant to inhabit, and there is no effective chemical control for $R$. solanacearum. In recent years, the increasing number of sites in Europe infested with potentially cold-adapted strains of $R$. solanacearum dramatically enhanced the threat posed to European potato crops $(9,20$, 30,32). Therefore, rapid early detection of this pathogen not only in tubers but also in soil or soil-related habitats is essential for disease management in the field to prevent losses and further pathogen spread.

$R$. solanacearum has been described as a species-complex, which was defined as a cluster of closely related strains with phenotypic and genotypic variation within the species (5). Based on $16 \mathrm{~S}$ rDNA sequence analysis, the $R$. solanacearum speciescomplex was described as including two closely related organisms, the blood disease bacterium (BDB) and Pseudomonas syzygii (26). Bacterial identification has often been predicated on analysis of rDNA sequence, so that a large amount of sequence data is available which has been used to reassess phylogenetic relationships. Several PCR-based methods for the detection of $R$. solanacearum have been described in the literature based on ribosomal gene sequences $(2,4,22,25,29,31)$. However, rDNA sequences from closely related bacteria are highly conserved, limiting the

Corresponding author: D. M. Jenkins; E-mail address: danielje@ hawaii.edu

doi:10.1094/PHYTO-98-9-1045

(c) 2008 The American Phytopathological Society value of rDNA analysis for studies of population genetics, epidemiological analysis, or the development of strain-specific detection methods (11). For detection of $R$. solanacearum, more discriminating primers have been used targeting functional genes such as endoglucanase (4), $h r p B$ (23), or a random fragment thought to be species specific (12).

The fliC gene coding for the flagellar subunit protein flagellin was used to develop a highly specific and sensitive polymerase chain reaction (PCR)-based detection system for $R$. solanacearum (24). Flagellin has a distinctive domainal structure, comprising conserved $\mathrm{N}$ - and $\mathrm{C}$-terminal regions. A central domain may vary considerably in both amino acid sequence and size, and is widely understood to be responsible for flagellar antigenic variability. By comparing the flagellin gene sequences from a number of related strains it is frequently possible to design oligonucleotide primers specific for $\mathrm{N}$-terminal and $\mathrm{C}$-terminal conserved regions. The predicted fliC protein of $R$. solanacearum also had well-conserved $\mathrm{N}$ - and C-terminal regions, separated by a divergent central domain that may allow design of $R$. solanacearum subspeciesspecific primer sets (27).

PCR methods are available and widely used for detection of $R$. solanacearum because of their sensitivity and specificity. In this study we sought alternative amplification methods that could be used in the field to facilitate detection without thermal cycling equipment. Loop-mediated amplification (LAMP), first described by Notomi et al. (19), was identified as a prospective method to achieve gene replication isothermally and without requiring denaturation of the template DNA. The LAMP method requires a set of four specially designed primers that recognize six distinct sequences and relies on autocycling strand displacing DNA synthesis by the Bst DNA polymerase large fragment. When combined with reverse transcription, this method can also amplify RNA sequences with high efficiency $(7,21)$. Furthermore, singlestranded DNA can be isolated from LAMP products (18).

The primers essential for the LAMP reaction are the inner primers (FIP and BIP) and the outer primers (F3 and B3), and the reaction is initiated by inner primer (either FIP or BIP) hybridi- 
zation to its respective priming site (F2c or B2c) on the target DNA. The outer primer (F3 or B3) secondarily hybridizes to its priming site (F3c or $\mathrm{B} 3 \mathrm{c}$ ) on the target DNA and initiates synthesis of new complementary sequence that displaces DNA sequences already extended from the inner primer. The result is a DNA sequence which can form stem-loop structures at both ends. This autoprimed "dumb-bell" structure is the starting material for LAMP auto-cycling amplification. Recently, it has been reported that the LAMP reaction can be accelerated using additional primers, termed loop primers (17), which hybridize to sections of the loop which were transcribed from the target DNA template. This additional priming accelerates the reaction and improves the selectivity because it requires transcription of the correct starting material. The LAMP reaction can be conducted under isothermal conditions ranging from 60 to $65^{\circ} \mathrm{C}$. The amplification products are stem-loop DNAs with several inverted repeats of the target, exhibiting cauliflower-like structure with multiple loops.

One of the characteristics of LAMP is its ability to rapidly synthesize a large amount of DNA. Accordingly, a large amount of by-product, pyrophosphate ion, is produced yielding a white precipitate of magnesium pyrophosphate and allowing rapid visual confirmation of the reaction (16). As in traditional PCR, the amplification products generated by LAMP can be verified with gel electrophoresis. The LAMP reaction produces many bands of different sizes, forming a ladder of DNA fragments of $100 \mathrm{bp}$ and larger. Production of the bands depends on the presence of the inner primers, the template, and the DNA polymerase. Specific amplification can be distinguished from nonspecific amplification by differences in the ladder pattern. Restriction digests and sequencing are also useful in confirming the structure of the amplified products. In this study, we evaluated the performance of the LAMP method targeting the fliC gene for detection of $R$. solanacearum.

\section{MATERIALS AND METHODS}

DNA preparation. Genomic DNA samples used for evaluation of primer specificity were prepared from 19 different strains of $R$. solanacearum, five strains of $\mathrm{BDB}$, and three nontarget bacteria, including one from the genus Ralstonia (Ralstonia eutropha strain H16), one common soilborne bacterium (Enterobacter strain A5150), and one plant pathogen (Erwinia carotovora subsp. carotovora strain CC26). One or two colonies from each strain were suspended in $100 \mu \mathrm{l}$ of lysis buffer $(20 \mathrm{mM}$ Tris-HCl, $\mathrm{pH} 8.0$, $2 \mathrm{mM}$ EDTA, and $1.2 \%$ Triton X-100) and boiled for $10 \mathrm{~min}$. The crude lysates were used as LAMP templates. Purified genomic DNAs were isolated with a commercial kit (Wizard Genomic DNA Purification Kit, Promega Corp., Madison, WI) according to the manufacturer's instructions. DNA concentrations were quantified photometrically (absorbance measurements at 260 and 280 nm with Nanodrop ND-1000 Spectrophotometer, NanoDrop Technologies, Inc., Rockland, DE).

Primer design for LAMP. Four primers used for LAMP reactions were designed to target the fliC sequence of $R$. solanacearum strain GMI1000 (GenBank No. NC 003295, 003296). The structure of the LAMP primers and their complementarity to target DNA used in this study is shown in Figure 1. A forward inner primer (FIP) consisted of F1c (the complementary sequence

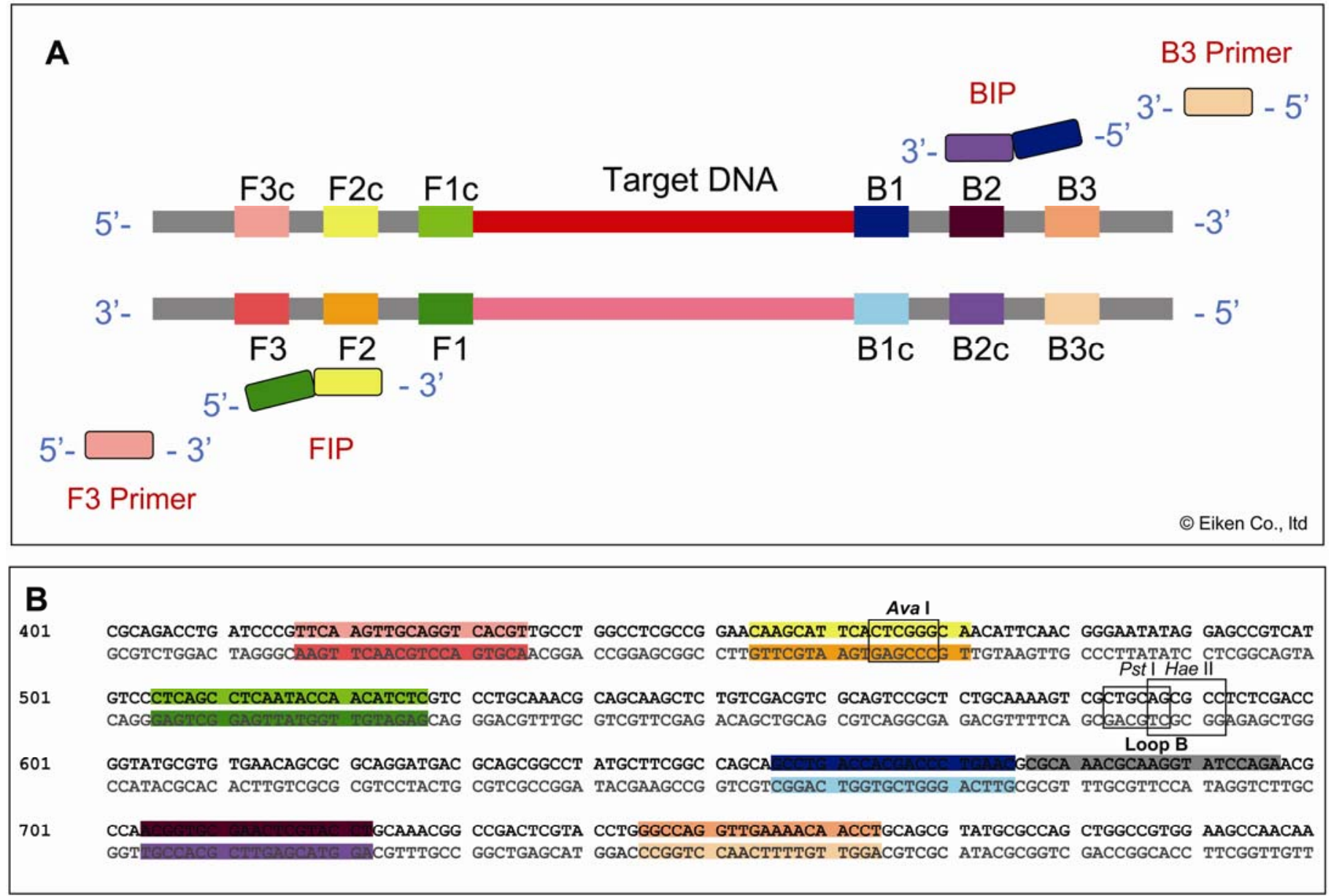

Fig. 1. Design of A, loop-mediated amplification (LAMP) primers, and B, Ralstonia solanacearum target DNA fragment. The target gene codes for the flagella subunit fliC of $R$. solanacearum strain GMI1000. The different colors correspond to the different primer sequences of the LAMP primer set shown in A. Restriction sites of enzymes AvaI, HaeII, and PstI, which were used to confirm the LAMP products, are shown in rectangular boxes. 
of F1) and F2, and a backward inner primer (BIP) consisted of B1c (the complementary sequence of B1) and B2. The outer primers $\mathrm{F} 3$ and $\mathrm{B} 3$ are required for initiation of LAMP reaction, and an additional loop primer was used in order to accelerate the process. To preclude the formation of hairpins or primer dimers that might result in false-positives, primer design software (PrimerExplorer V3, Eiken Co., Ltd., Japan) was used to identify a set of working primers and to ensure that specific primer combinations would not self hybridize. The software MFOLD (35), was used to verify the primer folding predictions. The resulting LAMP rsfliC primer set binds to an unambiguous region of the $\mathrm{fliC}$ gene that is unique from the binding sites of reported PCR primers such as Ral_fliC, Rsol_fliC primers (24). The sequences of each primer are shown in Table 1.

LAMP reaction. LAMP reactions were performed in $25 \mu \mathrm{l}$ (total volume) reaction mixtures containing $1.6 \mu \mathrm{M}$ FIP and BIP, $0.2 \mu \mathrm{M}$ concentrations of the $\mathrm{F} 3$ and $\mathrm{B} 3$ primer, $0.4 \mu \mathrm{M}$ concentrations of the loop B primer, $400 \mu \mathrm{M}$ deoxynucleoside triphosphates (dNTPs), 1.0 M betaine (Sigma-Aldrich Corp, St. Louis, MO), $20 \mathrm{mM}$ Tris- $\mathrm{HCl}(\mathrm{pH} \mathrm{8.8),} 10 \mathrm{mM} \mathrm{KCl}, 10 \mathrm{mM}$ $\left(\mathrm{NH}_{4}\right)_{2} \mathrm{SO}_{4}, 6 \mathrm{mM} \mathrm{MgSO}_{4}, 0.1 \%$ Triton $\mathrm{X}-100$, and template DNA. The reactions were carried out in 0.2-ml microtubes, using a thermal cycler for temperature control. The mixtures were heated to $95^{\circ} \mathrm{C}$ for $5 \mathrm{~min}$, and then chilled on ice prior to addition of $8 \mathrm{U}$ of $B s t$ DNA polymerase large fragment (New England Biolabs, Inc., Beverly, MA). Immediately after addition of the polymerase the mixture was incubated at $65^{\circ} \mathrm{C}$ for $60 \mathrm{~min}$. Termination of the reaction was achieved by heating to $80^{\circ} \mathrm{C}$ to denature the polymerase.

Analysis of LAMP products. The amplified products were electrophoresed at $85 \mathrm{~V}$ for 90 min through $2 \%$ agarose gel $(1 \times$ Tris-acetate-EDTA), followed by staining with ethidium bromide, using appropriate size markers (Hyper ladder II; Bioline USA, Inc., Randolph, MA). In addition, to confirm the structure, the amplified products were digested with several restriction endonucleases and their sizes were analyzed by electrophoresis. Based on analysis of the predicted amplified gene sequence (Fig. 1B), cleavage at $A v a$ I restriction site located on the FIP primer site would cause the LAMP product to be cut into 473-bp fragments by $A v a \mathrm{I}$ digestion. Likewise, digestion by HaeII would result in 225-bp predicted fragment size and digestion by PstI would result in 215-bp predicted fragment size. To confirm these predictions, $2.0 \mu \mathrm{l}$ of LAMP products digested with restriction enzyme were also subjected to electrophoresis on a $2 \%$ agarose gel. For comparison of the LAMP amplification to traditional PCR methods, the fliC gene was amplified using the primers and protocols as described in Schonfeld et al. (24).

Direct analysis of LAMP products. For visual assessment, white turbidity of the reaction mixture by magnesium pyrophosphate (by-product of LAMP) was detected by simple visual assessment.

Sensitivity of LAMP. A pure culture of $R$. solanacearum strain GMI1000 was plated on modified triphenyltetrazolium chloride (TZC) medium ( $0.8 \%$ peptone, $0.1 \%$ yeast extract, $1.8 \%$ agar, and $0.001 \% \mathrm{TZC}$ ) and incubated for $48 \mathrm{~h}$ at $28^{\circ} \mathrm{C}$. One colony was transferred and grown in PY medium $(0.5 \%$ dextrose, $1.0 \%$ peptone, $1.7 \%$ agar, and $0.001 \% \mathrm{TZC})$ at $28^{\circ} \mathrm{C}$ for $24 \mathrm{~h}$. The culture was diluted (approximately $10^{-1}$ dilution) with distilled water in a test tube to give a predetermined optical absorbance at $600 \mathrm{~nm}$ ( $A_{600}$ of 0.1 ; approximately $10^{8} \mathrm{CFU} / \mathrm{ml}$ ) as a stock sample. A 10 fold dilution series $\left(10^{-1}\right.$ to $\left.10^{-7}\right)$ in distilled water was made from the stock and plated onto TZC medium to estimate the colony number. Ten microliters of each dilution were further diluted by the addition of $80 \mu \mathrm{l}$ of distilled water and $10 \mu \mathrm{l}$ of $10 \times$ concentrated TE buffer (100 mM Tris- $\mathrm{HCl} \mathrm{pH}$ 8.0, and $10 \mathrm{mM}$ EDTA pH 8.0 ), incubated at $95^{\circ} \mathrm{C}$ for $10 \mathrm{~min}$, and centrifuged at $18,120 \times \mathrm{g}$ and $4^{\circ} \mathrm{C}$ for $5 \mathrm{~min}$. Five microliters of supernatant from each sample in TE buffer was then used for the LAMP process. Three replicates of each dilution were tested to assess the sensitivity of LAMP reaction.

To test the efficacy of the LAMP reaction in mixed cultures, supernatants from cultures of $R$. solanacearum strain GMI1000 were mixed with those from cultures of Enterobacter strain A5150 prior to assay with the LAMP process. Ten-microliter aliquots of the $R$. solanacearum cultures (from undiluted stock or from a $10^{-1}$ dilution in TE buffer) were mixed with different volumes (10 to $80 \mu \mathrm{l})$ of a culture of Enterobacter strain A5150, and subsequently diluted in TE buffer to the desired concentration of $R$. solanacearum. The mixed cultures were incubated at $95^{\circ} \mathrm{C}$ for $10 \mathrm{~min}$, and centrifuged at $18,120 \times g$ and $4^{\circ} \mathrm{C}$ for $5 \mathrm{~min}$. Five microliters of the resulting supernatants was then assayed using the LAMP process, taking three replicates of each mixed culture.

Application of LAMP for effluent water from wilted edible ginger plant. Edible ginger plants (Zingiber officinale) infected by $R$. solanacearum strain A4515 were used to demonstrate the application of LAMP technology in a natural media.

Three-month-old ginger plants grown in soil collected from a ginger farm on the island of Hawaii were inoculated by pouring $25 \mathrm{ml}$ of a culture of $R$. solanacearum A4515 strain (approximately $10^{8} \mathrm{CFU} / \mathrm{ml}$ ) over a wound cut into the rhizome with a scalpel. The plants were kept in pots in the greenhouse under regular sunlight and irrigated daily with $250 \mathrm{ml}$ of water. After plants exhibited symptoms of bacterial wilt, drainage water (approximately $100 \mathrm{ml}$ ) was collected after each daily irrigation for laboratory analysis.

A filtration technique was used with the drainage water to concentrate the bacteria and remove inhibitors of LAMP reaction. A total of $1.0 \mathrm{ml}$ of the sample was filtered on a commercial column with a $0.2 \mu \mathrm{m}$ polyvinylidene difluoride (PVDF) membrane (Ultra-free MC GV column, Millipore Corp., Bedford, MA) centrifuged at $1,000 \times g$ for $2 \mathrm{~min}$. To remove contaminants, the filter was then washed by applying $1.5 \mathrm{ml}$ of TE buffer to the column and centrifuging at $1,000 \times g$ for $2 \mathrm{~min}$. The column was then crushed with a pair of pliers and the PVDF membrane was cut out with a set of sterilized forceps. The extracted membrane was then vortexed with $50.0 \mu \mathrm{l}$ of TE buffer, incubated at $95^{\circ} \mathrm{C}$ for $5 \mathrm{~min}$, and centrifuged at $20,400 \times g$ for $5 \mathrm{~min}$. Five microliters of the resulting supernatant was then assayed using the LAMP reaction as described previously.

Viable colony count of $R$. solanacearum from drainage water samples. Drainage water samples collected from daily irrigation were applied for viable colony count. A 10-fold dilution series $\left(10^{-1}\right.$ to $\left.10^{-4}\right)$ in phosphate buffer $(0.01 \mathrm{M}$ phosphate, $\mathrm{pH}$ 6.9) was made from each sample and $100 \mu \mathrm{l}$ of each dilution was plated on a modified semiselective agar medium (SMSA), South Africa, (1.0\% peptone, $0.5 \%$ glycerol, $0.1 \%$ casein hydrolysate, $1.7 \%$ agar, $0.01 \%$ polymyxin $\mathrm{B}$ sulfate, $0.005 \% \mathrm{TZC}, 0.0025 \%$ bacitracin, $0.0025 \%$ cycloheximide, $0.0005 \%$ chloromycetin, $0.0005 \%$ crystal violet, and $0.00005 \%$ penicillin) selective for $R$. solanacearum (3).

Measurement of turbidity. Optical measurements were taken on 2.0- $\mu$ l samples using a commercial spectrophotometer (Nano-

TABLE 1. The rsfliC primer sequences for loop-mediated amplification replication of the flagellar gene $f_{l i C}$

\begin{tabular}{ll}
\hline Primer & Sequence \\
\hline rsfliC F3 & 5'-TTCAAGTTGCAGGTCACGT-3' \\
rsfliC B3 & 5'-AGGTTGTTTTCAACCTGGCC-3' \\
rsfliC FIP & 5'-GAGATGTTGGTATTGAGGCTGAGCAAGCATTCA- \\
& CTCGGGCA-3' \\
rsfliC BIP & 5'-GCCTGACCACGACCCTGAACAGGTACGAGTTCG- \\
& CACCGT-3' \\
rsfliC loop & 5'-CGCAAACGCAAGGTATCCAGA-3' \\
\hline a FIP consists of F2 and F1c sequences as shown on Figure 1. BIP consists of \\
B2 and B1c sequences.
\end{tabular}


drop ND-1000 Spectrophotometer). Absorbance spectra of positive LAMP reactions diluted in the unreacted mixture showed that the LAMP products could be detected at any wavelength in the visible spectra, and showed especially strong absorbance towards the lower wavelength end of the spectrum (data not shown). For further analysis, a wavelength of $400 \mathrm{~nm}$ was used in order to avoid interference from the strong UV absorbance of the single nucleosides in the reaction mix. Absorbance readings were recorded for LAMP reaction mixtures from samples of the drainage water in the infected ginger experiments, and corrected for the background absorbance of a reaction mixture without template DNA.

Statistical data analysis. To determine an absorbance threshold for classification of positive LAMP reactions, 15 samples of sterile water were assayed using the LAMP reaction. The classification threshold was taken as three standard errors of the observed absorbance values above the mean absorbance values for all of the negative controls. This threshold corresponds to the value at which at least $99 \%$ of all negative samples will correctly be classified as negative.

To determine the detection limit for LAMP using absorbance measurements, a commercial graphing software (SigmaPlot 8.0, Systat Software Inc., San Jose, CA) was used to fit the observed absorbance data to the corresponding colony counts from the original samples according to a simple sigmoidal equation:

$$
A_{400}=\frac{a}{1+e^{\left(\frac{x_{0}-x}{b}\right)}}
$$

where $A_{400}$ is the absorbance at $400 \mathrm{~nm} ; a, b$, and $x_{0}$ are fitted coefficients; and $x$ equals the logarithm of the colony count $y$ in CFU/ml: $x=\log _{10}(y)$.

The fitted colony count in CFU/ml corresponding to the absorbance value equal to three standard errors of the regression

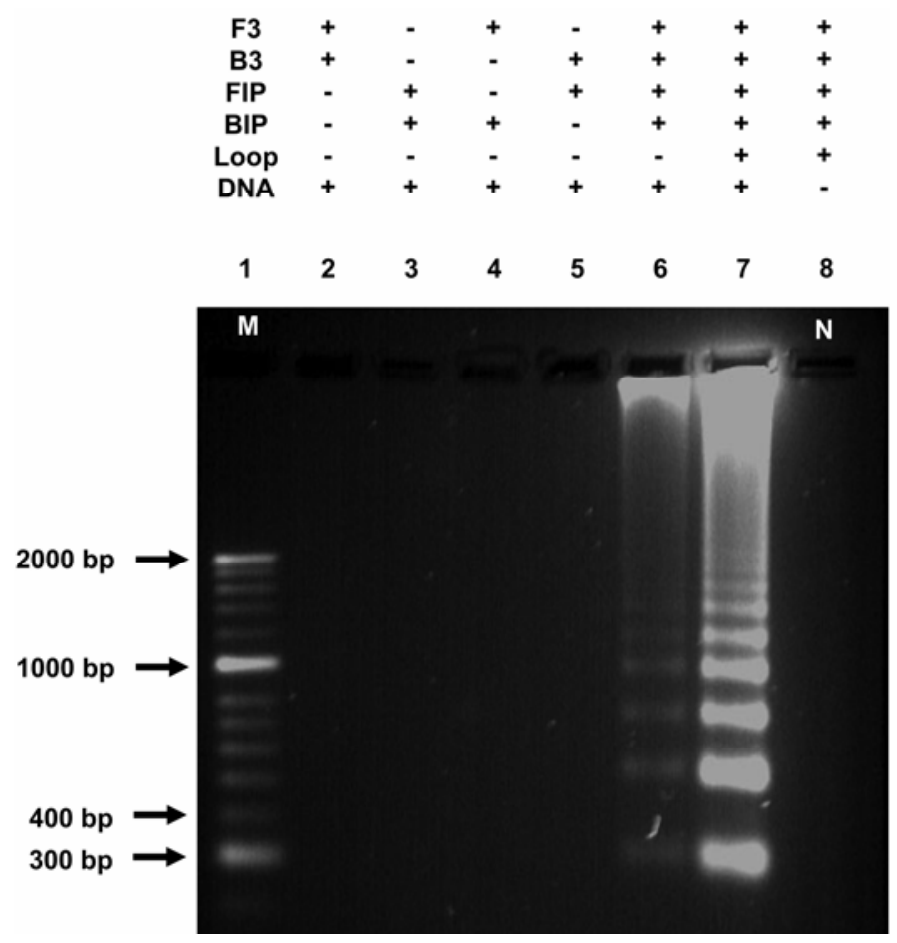

Fig. 2. Primer (F3, B3, FIP, BIP, and Loop) combinations applied to Ralstonia solanacearum genomic DNA (DNA) to determine the primers required for loop-mediated amplification (LAMP) and to observe LAMP acceleration by the loop primer. One microliter aliquots (out of $25 \mu \mathrm{l}$ total in the reaction solutions) were applied to $2 \%$ agarose gel electrophoresis and stained with ethidium bromide. All four primers F3, B3, FIP, and BIP are required for successful LAMP reaction (lane 6). The LAMP reaction was accelerated by adding a loop primer (lane 7). Lane $1(\mathrm{M})$ has size markers (BIOLINE), and lane $8(\mathrm{~N})$ is a control with no template DNA. was taken as the detection limit, which by definition is the minimum amount of bacteria required to ensure that a positive reaction will be observed at least $99 \%$ of the time.

\section{RESULTS}

Primers required for LAMP reaction. A successful LAMP reaction with species-specific primers produced many bands of different sizes (Fig. 2) in a reproducible ladder-like pattern. When the sample tube did not contain selected target DNA or any of the primers, F3, B3, FIP, and BIP, no amplification was observed. To confirm that the amplification products had the predicted DNA structures, they were digested with restriction enzymes and the sizes of the fragments were analyzed by electrophoresis. AvaI cuts on the F2 fragment of fliC amplicons, and HaeII and PstI both cut between the F1 (F1c) and the B1c (B1) fragments. The sizes of the fragments generated after digestion corresponded to the sizes predicted theoretically from the expected DNA structures: $473 \mathrm{bp}$ for AvaI; 225 bp for HaeII, and; 215 bp for PstI (Fig. 3).

Visual detection of LAMP reaction. Iwamoto et al. (8) reported that a LAMP reaction mixture containing amplified fragments turned green after the addition of SYBR Green I, whereas a solution with no amplicons retained the original orange color of SYBR Green I. Thus, the results of the LAMP reactions could be confirmed visually. We were unable to detect any differences between successful and unsuccessful amplifications based on visual inspection of SYBR Green I. We were, however, able to visually confirm successful LAMP reactions by observation of a magnesium pyrophosphate precipitate (Fig. 4). One of the characteristics of LAMP is its ability to amplify a large amount of target DNA rapidly, making it easy to identify through by-products of DNA strand synthesis such as pyrophosphate. The increase of white turbidity can be measured quantitatively in real-time $(1,13-$ $16,28,33)$.

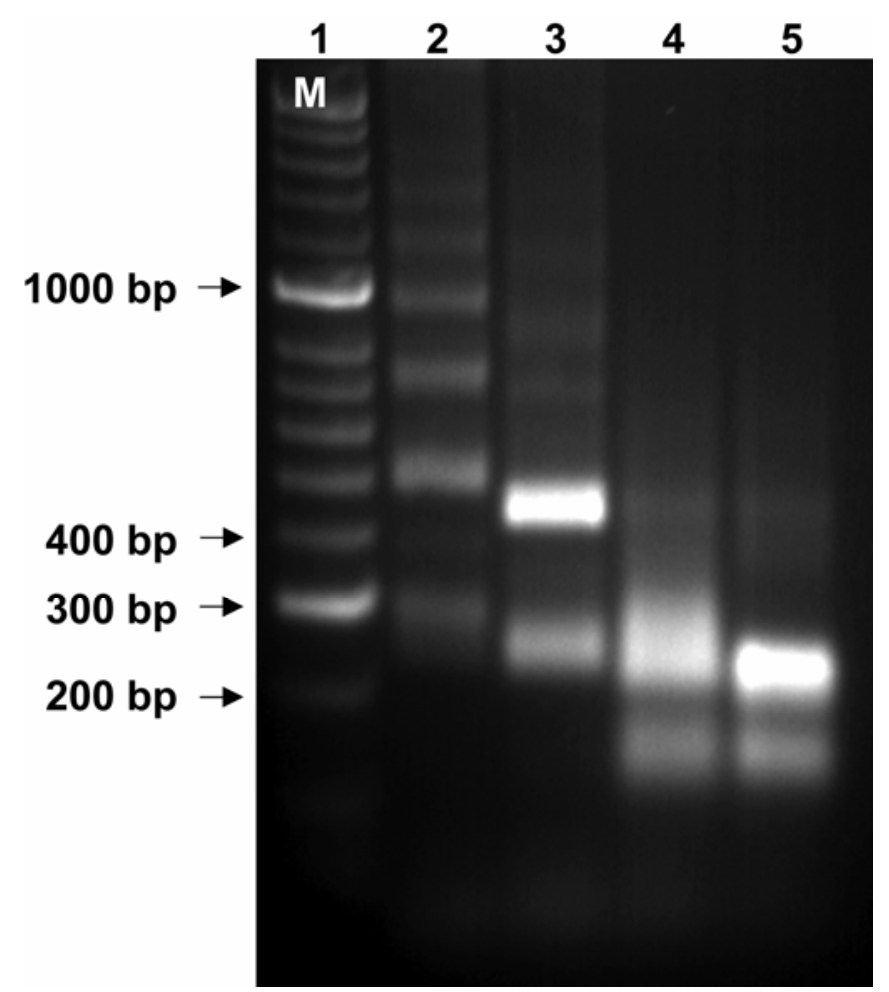

Fig. 3. Restriction enzyme digestion of loop-mediated amplification (LAMP) products. The LAMP products (lane 2) were digested by AvaI (lane 3), HaeII (lane 4), and PstI (lane 5), applied to 2\% agarose gel electrophoresis, and stained with ethidium bromide. Expected sizes of digested LAMP products were as follows: AvaI, 473 bp; HaeII, 25 bp; and PstI, 215 bp. Lane 1 (M) has size markers (BIOLINE). 


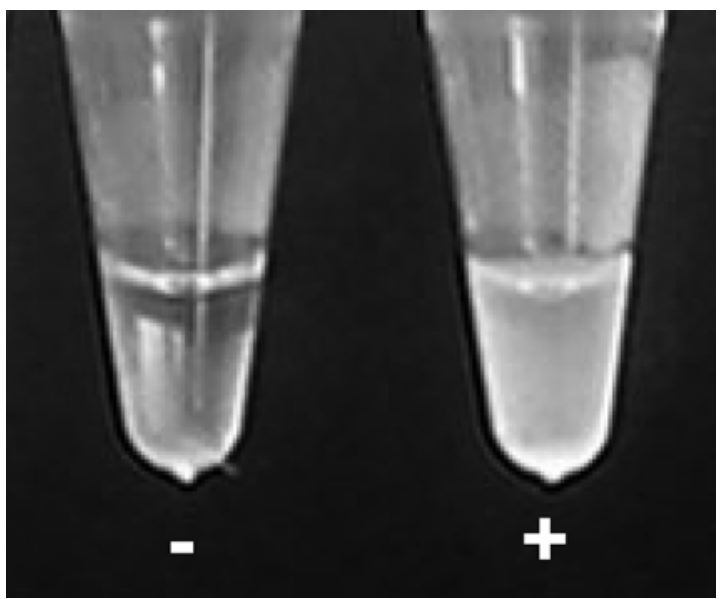

Fig. 4. Visual assessment of DNA proliferation by loop-mediated amplification. The turbidity indicating a positive reaction $(+)$ is caused by insoluble pyrophosphate ions produced during DNA synthesis, whereas the negative control (-) remains clear.
Analysis of primer selectivity. The LAMP studies reported previously were conducted with purified genomic DNA from different strains of $R$. solanacearum (races 1, 2, 3, and 4, and $R$. solanacearum $\mathrm{BDB}$ ) and other soilborne bacteria strains (E. carotovora subsp. carotovora strain CC26, Enterobacter strain A5150, and $R$. eutropha strain H16). A summary of all bacterial strains tested with the LAMP reaction is given in Table 2. With the exception of all five blood-disease strains, all strains tested that belong to the species complex of $R$. solanacearum, including the Race 3 strains, gave an amplification product with a ladder-like pattern typical of LAMP, whereas LAMP amplification products were not observed following LAMP reaction with other soilborne bacteria strains (Fig. 5).

Sensitivity of LAMP. The detection limit, determined as the minimum amount of culturable bacteria required to induce an observable LAMP reaction, was determined to be between $1.1 \times$ $10^{4}$ and $1.3 \times 10^{6} \mathrm{CFU} / \mathrm{ml}$ for $R$. solanacearum strain GMI1000 based on visual detection of amplicons run through an agarose gel. The detection limit for other positive $R$. solanacearum strains varied from $6.0 \times 10^{4}$ to $1.5 \times 10^{6} \mathrm{CFU} / \mathrm{ml}$ (data not shown). In

TABLE 2. A summary of strains used in this study

\begin{tabular}{|c|c|c|c|c|c|}
\hline Species & Strain & No. of strains & Race & Host plants (no. of strains) & LAMPa $^{a}$ \\
\hline \multirow[t]{5}{*}{ Ralstoia solanacearum } & & 4 & 1 & Tomato (2), squash (1), peanut (1) & + \\
\hline & & 6 & 2 & Banana (5), heliconia (1) & + \\
\hline & & 5 & 3 & Potato (2), geranium (2), S. phurjea (1) & + \\
\hline & & 4 & 4 & Ginger (4) & + \\
\hline & & 5 & BDB & Banana (5) & - \\
\hline Ralstonia eutropha & H16 & 1 & $\ldots$ & N/A & - \\
\hline Erwinia carotovora subsp. carotovora & $\mathrm{CC} 26$ & 1 & $\ldots$ & Potato & - \\
\hline Enterobacter & A5150 & 1 & $\ldots$ & N/A & - \\
\hline
\end{tabular}

${ }^{a}$ Loop-mediated amplification.
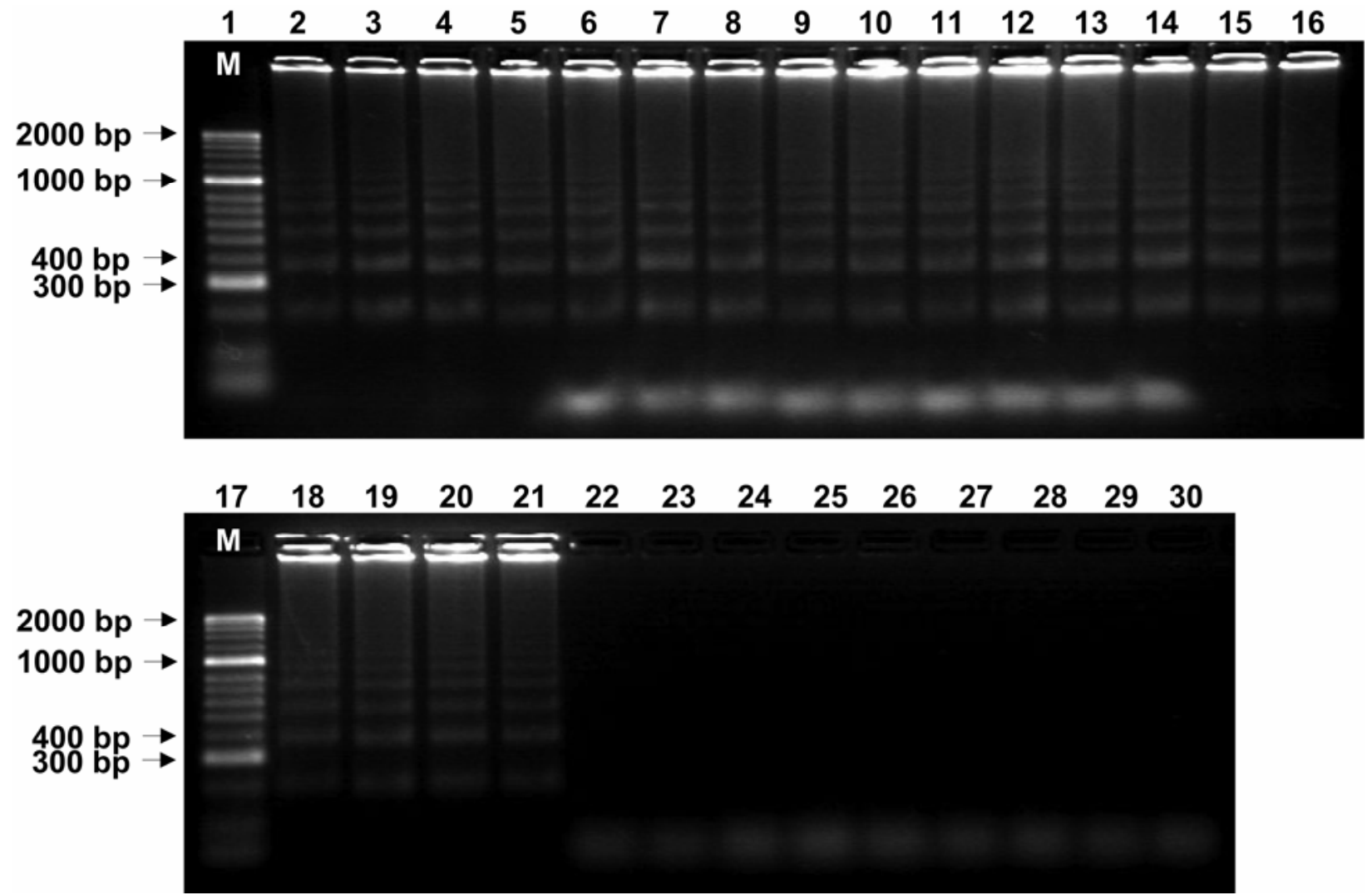

Fig. 5. Gel electrophoresis applied to loop-mediated amplification products from different strains of Ralstonia solanacearum (lanes 2 to 5: race 1; GMI1000, A3450, A3777, and A3780. Lanes 7 to 12: race 2; A3381, A3908, A4125, A4126, A4127, and A4128. Lanes 6 to 16: race3; A5286, A5289, A5290, and A5291. Lanes 18 to 21: race 4; A3786, A4515, A5190, and A5192), and nonspecific bacteria (lanes 22 to 26: BDB strains; A4606, A4608, A4609, A4611, and A4612. Lane 27: Ralstonia eutropha; H16. Lane 28: Erwinia carotovora subsp. carotovora; CC26. Lane 29: Enterobacter; A5150. Lane 30: negative control. Lanes 1 and 17 have size markers (BIOLINE). 
mixed cultures the detection limit of the LAMP reaction was not affected by the presence of Enterobacter strain A5150, even at concentrations of up to $1000 \times$ that of $R$. solanacearum.

Application of LAMP for environmental samples. We observed that LAMP could reliably be used to amplify the target gene from effluent water samples with various concentrations of $R$. solanacearum. The filtration step was used to preconcentrate the pathogen and to remove inhibitors of the LAMP reaction. Statistical analysis of the turbidity data showed that the detection limit based on quantitative absorbance measurements was $10^{5}$ $\mathrm{CFU} / \mathrm{ml}$, although positive test results were observed for samples down to near $10^{2} \mathrm{CFU} / \mathrm{ml}$ (Fig. 6).

\section{DISCUSSION}

We used a novel nucleic acid amplification method called LAMP for detection of $R$. solanacearum. This technology has advantages over PCR and immunological methods. The most significant advantage of LAMP is its ability to amplify specific sequences of DNA at $65^{\circ} \mathrm{C}$ without thermal cycling. The reaction itself occurs within $60 \mathrm{~min}$ and only $3 \mathrm{~h}$ are required for a complete detection from cultured cells. These characteristics confer some advantages for incorporation of LAMP into a simple disposable detection system (10) for field detection of $R$. solanacearum. We developed an $R$. solanacearum species-specific LAMP method by designing a primer set "rsfliC" consisting of five primers; F3, B3, FIP, BIP, and loop. The sequences of the rsfliC primer set were designed based on the published sequence of $R$. solanacearum strain GMI1000 (GenBank nos. NC 003295, and 003296), targeting the flagellar subunit, flagellin gene fliC.

LAMP amplification products using the rsfliC primer set had multiple fragment sizes that were typical for the LAMP process. Amplification of the target sequence was confirmed by restriction enzyme digestion and DNA sequencing (data not shown) of the amplicons. The rsfliC LAMP primer set was shown to be $R$. solanacearum species specific as it resulted in amplification from $R$. solanacearum strains, but not from the related BD bacterial strains or other soilborne bacteria species such as E. carotovora subsp. carotovora strain CC26 and Enterobacter sp. strain A5150. Notably, the primer set was positive against all tested race 3 strains of $R$. solanacearum which are considered of high international impact. This result is consistent with results of PCR amplification of the same gene using Ral_fliC or Rsol_fliC primers,

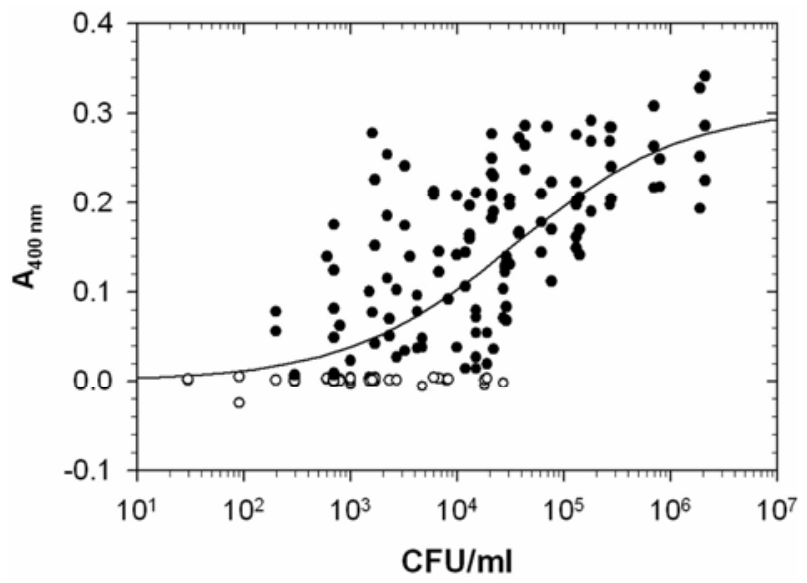

Fig. 6. Absorbance of loop-mediated amplification reaction mixture at $400 \mathrm{~nm}$ versus Ralstonia solanacearum population of collected drainage water samples. Solid circles indicate samples classified as "positive" for $R$. solanacearum, and open circles indicate samples classified as negative based on optical absorbance measurements. The line indicates the best fit sigmoidal curve of the form of equation $1\left(R^{2}=0.54\right.$; standard error $=0.066$ absorbance units; detection limit $=10^{5} \mathrm{CFU} / \mathrm{ml} ; a=0.307 ; b=0.791 ; x_{0}=4.541$ ). indicating that the flagellin gene $f l i C$ is a good candidate to target for species identification.

As in any DNA polymerization reaction, the LAMP process results in the insoluble by-product magnesium pyrophosphate. However, the high yield of the LAMP reaction results in a highly turbid solution with a large amount of precipitate that can be easily recognized by visual inspection. Our results confirm that a successful LAMP reaction could be identified visually or with the aid of a spectrophotometer, with only marginal improvement in classification accuracy using the analytical instrument (data not shown).

LAMP has high specificity and speed, attributed to autocycling amplification under isothermal conditions by using four primers. The rsfliC LAMP primer set used for $R$. solanacearum detection is highly sensitive, as it detects approximately $10^{4}$ to $10^{6} \mathrm{CFU} / \mathrm{ml}$ of $R$. solanacearum strain GMI1000 in less than $1 \mathrm{~h}$ under isothermal conditions. The visual assessment of LAMP products demonstrates the possibility of applying this method for field detection. However, more definitive confirmation methods such as restriction analysis, DNA hybridization, or DNA sequencing are still needed. Recently, protocols for isolation of single stranded DNA from LAMP products were reported (18). This may facilitate, for example, the adaptation of LAMP for use with an electrochemical DNA hybridization sensor (10) for more absolute confirmation in the field.

\section{ACKNOWLEDGMENTS}

We gratefully acknowledge support from the USDA (NRI project 2005-55605-16683 and TSTAR project HAW00559-04G).

\section{LITERATURE CITED}

1. Aoi, Y., Hosogai, M., and Tsuneda, S. 2006. Real-time quantitative LAMP (loop-mediated isothermal amplification of DNA) as a simple method for monitoring ammonia-oxidizing bacteria. J. Biotechnol. 125:484-491.

2. Boudazin, G., Le Roux, A. C., Josi, K., Labarre, P., and Jouan, B. 1999. Design of division specific primers of Ralstonia solanacearum and application to the identification of European isolates. Eur. J. Plant Pathol. 105:373-380.

3. Englerbrecht, M. C. 1994. Modification of a semi-selective medium for the isolation and quantification of Pseudomonas solanacearum. ACIAR Bact. Wilt Newsl. 10:3-5.

4. Fegan, M., Taghavi, M., Sly, L. I., and Hayward, A. C. 1998. Phylogeny, diversity and molecular diagnostics of Ralstonia solanacearum. SpringerVerlag, Berlin.

5. Gillings, M. R., and Fahy, P. 1994. Genomic Fingerprinting: Towards a Unified View of Pseudomonas solanacearum Species Complex. CAB International, Wallingford, UK.

6. Hartman, G. L., Hong, W. F., and Wang, T. C. 1991. Survey of bacterial wilt on fresh market hybrid tomatoes in Taiwan. Plant Prot. Bull. 33:197-203.

7. Hong, T. C., Mai, Q. L., Cuong, D. V., Parida, M., Minekawa, H., Notomi, T., Hasebe, F., and Morita, K. 2004. Development and evaluation of a novel loop-mediated isothermal amplification method for rapid detection of severe acute respiratory syndrome coronavirus. J. Clin. Microbiol. 42:1956-1961.

8. Iwamoto, T., Sonobe, T., and Hayashi, K. 2003. Loop-mediated isothermal amplification for direct detection of Mycobacterium tuberculosis complex, $M$. avium, and $M$. intracellulare in sputum samples. J. Clin. Microbiol. 41:2616-2622.

9. Janse, J. D., Araluppan, F. A. X., Schans, J., Wenneker, M., and Westerhuis, W. 1998. Experiences with Bacterial Brown Rot Ralstonia solanacearum Biovar 2, Race 3, in The Netherlands. Springer-Verlag, Berlin, Germany.

10. Jenkins, D. M., Chami, B., Kreuzer, M., Presting, G., Alvarez, A. M., and Liaw, B. Y. 2006. Hybridization probe for femtomolar quantification of selected nucleic acid sequences on a disposable electrode. Anal. Chem. 78:2314-2318.

11. Jensen, M. A., Webster, J. A., and Straus, N. 1993. Rapid identification of bacteria on the basis of polymerase chain reaction-amplified ribosomal DNA spacer polymorphisms. Appl. Environ. Microbiol. 59:945-952.

12. Lee, Y. A., and Wang, C. C. 2000. The design of specific primers for the detection of Ralstonia solanacearum in soil samples by polymerase chain reaction. Bot. Bull. Acad. Sinica 41. 
13. Maeda, H., Kokeguchi, S., Fujimoto, C., Tanimoto, I., Yoshizumi, W., Nishimura, F., and Takashiba, S. 2005. Detection of periodontal pathogen Porphyromonas gingivalis by loop-mediated isothermal amplification method. FEMS Immunol. Med. Microbiol. 43:233-239.

14. Maruyama, F., Kenzaka, T., Yamaguchi, N., Tani, K., and Nasu, M. 2003. Detection of bacteria carrying the stx2 gene by in situ loop-mediated isothermal amplification. Appl. Environ. Microbiol. 69:5023-5028.

15. Mori, Y., Kitao, M., Tomita, N., and Notomi, T. 2004. Real-time turbidimetry of LAMP reaction for quantifying template DNA. J. Biochem. Biophys. Methods 59:145-157.

16. Mori, Y., Nagamine, K., Tomita, N., and Notomi, T. 2001. Detection of loop-mediated isothermal amplification reaction by turbidity derived from magnesium pyrophosphate formation. Biochem. Bioph. Res. Co. 289:150-154

17. Nagamine, K., Hase, T., and Notomi, T. 2002. Accelerated reaction by loop-mediated isothermal amplification using loop primers. Mol. Cell. Probe 16:223-229.

18. Nagamine, K., Kuzuhara, Y., and Notomi, T. 2002. Isolation of singlestranded DNA from loop-mediated isothermal amplification products. Biochem. Bioph. Res. Co. 290:1195-1198.

19. Notomi, T., Okayama, H., Masubuchi, H., Yonekawa, T., Watanabe, K., Amino, N., and Hase, T. 2000. Loop-mediated isothermal amplification of DNA. Nucleic Acids Res. 28:E63.

20. Olsson, K. 1976. Experience of brown rot caused by Pseudomonas solanacearum (Smith) in Sweden. OEPP/EPPO Bull. 6:199-207.

21. Parida, M., Posadas, G., Inoue, S., Hasebe, F., and Morita, K. 2004. Realtime reverse transcription loop-mediated isothermal amplification for rapid detection of West Nile virus. J. Clin. Microbiol. 42:257-263.

22. Pastrik, K. H., and Maiss, E. 2000. Detection of Ralstonia solanacearum in potato tubers by polymerase chain reaction. J. Phytopathol. 148:619626.

23. Poussier, S., Prior, P., Luisetti, J., Hayward, C., and Fegan, M. 2000. Partial sequencing of the hrpB and endoglucanase genes confirms and expands the known diversity within the Ralstonia solanacearum species complex. Syst. Appl. Microbiol. 23:479-486.

24. Schonfeld, J., Heuer, H., Van Elsas, J. D., and Smalla, K. 2003. Specific and sensitive detection of Ralstonia solanacearum in soil on the basis of PCR amplification of fliC fragments. Appl. Environ. Microbiol. 69:72487256.

25. Seal, S. E., Jackson, L. A., Young, J. P., and Daniels, M. J. 1993. Differentiation of Pseudomonas solanacearum, Pseudomonas syzygii, Pseudomonas pickettii and the blood disease bacterium by partial 16S rRNA sequencing: Construction of oligonucleotide primers for sensitive detection by polymerase chain reaction. J. Gen. Microbiol. 139:1587-1594.

26. Taghavi, M., Hayward, C., Sly, L. I., and Fegan, M. 1996. Analysis of the phylogenetic relationships of strains of Burkholderia solanacearum, Pseudomonas syzygii, and the blood disease bacterium of banana based on 16S rRNA gene sequences. Int. J. Syst. Bacteriol. 46:10-15.

27. Tans-Kersten, J., Huang, H., and Allen, C. 2001. Ralstonia solanacearum needs motility for invasive virulence on tomato. J. Bacteriol. 183:35973605 .

28. Thai, H. T. C., Le, M. Q., Vuong, C. D., Parida, M., Minekawa, H., Notomi, T., Hasebe, F., and Morita, K. 2004. Development and evaluation of a novel loop-mediated isothermal amplification method for rapid detection of severe acute respiratory syndrome coronavirus. J. Clin. Microbiol. 42:1956-1961.

29. van der Wolf, J. M., Vriend, S. G. C., Kastelein, P., Nijhuis, E. H., van Bekkum, P. J., and van Vuurde, J. W. L. 2000. Immunofluorescence colony-staining (IFC) for detection and quantification of Ralstonia (Pseudomonas) solanacearum biovar 2 (race 3) in soil and verification of positive results by PCR and dilution plating. Eur. J. Plant Pathol. 106:123133.

30. Van Elsas, J. D., Kastelein, P., van Bekkum, P., van der Wolf, J. M., de Vries, P. M., and van Overbeek, L. S. 2000. Survival of Ralstonia solanacearum biovar 2 , the causative agent of potato brown rot, in field and microcosm soils in temperate climates. Phytopathology 90:1358-1366.

31. Weller, S. A., Elphinstone, J. G., Smith, N. C., Boonham, N., and Stead, D. E. 2000. Detection of Ralstonia solanacearum strains with a quantitative, multiplex, real-time, fluorogenic PCR (TaqMan) assay. Appl. Environ. Microbiol. 66:2853-2858.

32. Wullings, B. A., van Beuningen, A. R., Janse, J. D., and Akkermans, A. D. L. 1998. Detection of Ralstonia solanacearum, which causes brown rot of potato, by fluorescent in situ hybridization with 23S rRNA-targeted probes. Appl. Environ. Microbiol. 64:4546-4554.

33. Yano, A., Ishimaru, R., and Hujikata, R. 2007. Rapid and sensitive detection of heat-labile I and heat-stable I enterotoxin genes of enterotoxigenic Escherichia coli by loop-mediated isothermal amplification. J. Microbiol. Methods 68:414-420.

34. Yu, Q., Alvarez, A. M., Moore, P. H., Zee, F., Kim, M. S., de Silva, A., Hepperly, P. R., and Ming, R. 2003. Molecular diversity of Ralstonia solanacearum isolated from ginger in Hawaii. Phytopathology 93:11241130.

35. Zuker, M. 2003. Mfold web server for nucleic acid folding and hybridization prediction. Nucleic Acids Res. 31:3406-3415. 